\title{
Involvement of enzymes of amino acid metabolism and tricarboxylic acid cycle in bovine oocyte maturation in vitro
}

\author{
P. Cetica, L. Pintos, G. Dalvit and M. Beconi* \\ Area of Biochemistry, School of Veterinary Sciences, University of Buenos Aires, Chorroarín 280, \\ (C1427CWO) Buenos Aires, Argentina
}

Few studies demonstrate at a biochemical level the metabolic profile of both cumulus cells and the oocyte during maturation. The aim of the present study was to investigate the differential participation of enzymatic activity in cumulus cells and in the oocyte during in vitro maturation (IVM) by studying the activity of enzymes involved in the control of amino acid metabolism, alanine aminotransferase (ALT) and aspartate aminotransferase (AST); and the tricarboxylic acid (TCA) cycle, isocitrate dehydrogenase (IDH) and malate dehydrogenase (MDH). No NAD-dependent isocitrate dehydrogenase (NAD-IDH) activity was recorded in cumulus-oocyte complexes (COCs). ALT, AST, NADP-dependent isocitrate dehydrogenase (NADP-IDH) and MDH enzymatic units remained constant in cumulus cells and oocytes during IVM. Specific activities increased in oocytes and decreased in cumulus cells as a result of IVM $(P<0.05)$. Similar activity of both transaminases was detected in cumulus cells, unlike in the oocyte, in which activity of AST was 4.4 times greater than that of ALT $(P<0.05)$. High NADP-IDH and MDH activity was detected in the oocyte. Addition of alanine, aspartate, isocitrate + NADP, oxaloacetate or malate + NAD to maturation media increased the percentage of denuded oocytes reaching maturation $(P<0.05)$, in contrast to COCs in which differences were not observed by addition of these substrates and co-enzymes. The activity of studied enzymes and the use of oxidative substrates denotes a major participation of transaminations and the TCA cycle in the process of gamete maturation. The oocyte thus seems versatile in the use of several oxidative substrates depending on the redox state.

\section{Introduction}

Current knowledge of the requirements of the bovine oocyte necessary for reaching normal in vitro maturation (IVM) and the metabolic profile of the oocyte is insufficient. As meiosis readily occurs in vitro, metabolic studies on the maturation process are scarce compared with those carried out on embryo development. However, the oocyte cytoplasm is known to provide the appropriate metabolic machinery for the production of energy required for cellular function during maturation, fertilization and early embryo development (Gardner, 1998). Application of knowledge gained about cytoplasmic changes during maturation may result in improved IVM and overall in vitro embryo production (Bavister et al., 1992; Krisher and Bavister, 1998; Sutton et al., 2003c).

Appropriate oocyte maturation depends largely on the presence of surrounding cumulus cells that perform nutritive and regulatory functions during this process, as removal of cumulus cells before maturation results in compromised maturation, fertilization and embryo

\footnotetext{
*Correspondence
}

Email: beconi@fvet.uba.ar development compared with removal of cumulus cells after IVF (Zhang et al., 1995; Cetica et al., 1999a; Fatehi et al., 2002). Several authors have suggested that the fate of glucose within cumulus cells is primarily the glycolytic pathway (Zuelke and Brackett, 1992; Cetica et al., 1999b, 2002; Sutton et al., 2003a). Cumulus cells would thus be in charge of producing metabolites derived from glucose degradation to be used as oxidative substrates by the oocyte (Buccione et al., 1990; Brackett and Zuelke, 1993; Cetica et al., 1999b). In rodents, oocytes free of somatic cells underwent spontaneous maturation when cultured in the presence of pyruvate or oxaloacetate, but failed to mature with glucose, lactate or phosphoenolpyruvate, indicating that oocyte maturation is sustained by the tricarboxylic acid (TCA) cycle (Biggers et al., 1967). It was postulated that pyruvate, glycine and glutamine uptake by bovine oocytes during maturation is one of the main pathways to obtain energy via the TCA cycle (Zuelke and Brackett, 1993; Rieger and Loskutoff, 1994). The presence of certain amino acids in maturation media increases the percentage of successful IVF cycles and the number of bovine embryos that reach the blastocyst stage. It was observed that a combination of glucose and amino acids in a given maturation medium free of proteins improved embryo development, 
whereas pyruvate combined with glucose or glutamine in the same medium led to a low percentage of embryo production (Krisher and Bavister, 1998; Rose-Hellekant et al., 1998).

The study of key enzyme activities responsible for controlling the rate of a metabolic pathway may be used to determine the participation of a given metabolic route in the cells under study. So far, no studies have been carried out to determine the activity of enzymes involved in the metabolism of amino acids and the TCA cycle in bovine cumulus-oocytes complexes (COCs) during IVM.

The first step in amino acid catabolism consists of the elimination of the alpha amino nitrogen atom by transamination, after which the resulting carbon skeleton is degraded to obtain energy. As the reactions catalysed by transaminases are reversible, they may catalyse amino acid reactions of catabolism or biosynthesis. Alanine aminotransferase (ALT) and aspartate aminotransferase (AST) are present in most mammalian tissues and play a key role in amino acid metabolism (Torchinsky, 1987). No isoenzymes have been described for ALT, but two isoforms have been identified for AST, a cationic or mitochondrial isoform and an anionic or cytosolic isoform (Schwartz, 1971).

Metabolites arising from carbohydrates, lipids and proteins are oxidized via the TCA cycle. During the course of the cycle, reduction equivalents are produced by specific dehydrogenases, which are re-oxidized in the respiratory chain generating ATP in the process of oxidative phosphorylation. Isocitrate dehydrogenase (IDH) is considered the main key enzyme of the TCA cycle; three isoenzymes, two mitochondrial and one cytosolic have been described. The mitochondrial isoenzymes use NAD and NADP as electron acceptors, unlike the cytosolic isoform that requires only NADP. Enzyme activity depends on ATP:ADP and $\mathrm{NAD}(\mathrm{P})$ : NAD $(\mathrm{P}) \mathrm{H}$ ratios (Hansford, 1980; Clarenburg, 1992). Malate dehydrogenase (MDH) performs a key function in the passage of reduction equivalents through the internal mitochondrial membrane as a result of the presence of cytosolic and mitochondrial isoenzymes. Oxaloacetate and NADH are impermeable to this membrane, unlike malate which can enter mitochondria (Clarenburg, 1992). Kitto (1969) observed that the cytosolic isoenzyme is inhibited by high malate concentrations and the mitochondrial isoenzyme is inhibited by high oxaloacetate concentrations.

Few studies demonstrate at a biochemical level the metabolic profile of both cumulus cells and the oocyte during maturation. More thorough knowledge of the activity of key enzymes that control the flow of metabolites in COCs will contribute to elucidate their nutritional requirements during IVM. Cetica et al. (2002) determined the activity of key enzymes that regulate glycolysis, the pentose phosphate pathway and lipolysis. The aim of the present study was to investigate the differential participation of enzymatic activity in cumulus cells and in the oocyte during IVM, by studying the activity of enzymes involved in the control of amino acid metabolism (ALT and AST) and the TCA cycle (IDH and $\mathrm{MDH}$.

\section{Materials and Methods}

\section{Materials}

All chemicals were purchased from Sigma Chemical Company (St Louis, MO), except for medium 199 (Earle's salts, L-glutamine, 2.2 mg sodium bicarbonate $\mathrm{I}^{-1}$ ), which was obtained from GIBCO BRL (Grand Island, NY).

\section{Recovery and classification of COCs}

Bovine ovaries were obtained from an abattoir within 30 min after the animals were killed and were stored at $30^{\circ} \mathrm{C}$ during the $2 \mathrm{~h}$ journey to the laboratory. Ovaries were washed in physiological saline containing 100000 iu penicillin $\mathrm{I}^{-1}$ and $100 \mathrm{mg}$ streptomycin $\mathrm{I}^{-1}$. COCs were recovered by aspiration of antral follicles (2$5 \mathrm{~mm}$ in diameter) and classified according to cumulus morphology under a stereomicroscope. Only oocytes completely surrounded by compact and thick cumulus were used.

\section{In vitro maturation of oocytes}

COCs were cultured in medium 199 supplemented with $10 \%(\mathrm{v} / \mathrm{v})$ steer serum and $50 \mathrm{mg}$ gentamicine sulphate $\mathrm{I}^{-1}$ under paraffin oil at $39^{\circ} \mathrm{C}$ for $22-24 \mathrm{~h}$ in an atmosphere of $5 \% \mathrm{CO}_{2}$ with humidified air.

Meiotic maturation was evaluated using $10 \%$ of samples. Oocytes were placed in a hypotonic medium of $10 \mathrm{~g}$ sodium citrate $\mathrm{I}^{-1}$ at $37^{\circ} \mathrm{C}$ for $15 \mathrm{~min}$, fixed on a slide with acetic acid-alcohol (Tarkowski, 1966), stained with 5\% (v/v) Giemsa for 15 min and observed under a light microscope at $\times 100$ and $\times 400$. Oocytes were considered mature when metaphase II chromosome configuration was present.

\section{Denuded oocytes}

Immature or matured oocytes were completely denuded by vortex agitation in sterile physiological saline for $1 \mathrm{~min}$ and then collected with a pipette to separate them from cumulus cells. Denuded oocytes were washed twice in the same medium to eliminate residual cumulus cells.

\section{Preparation of enzymatic extracts}

Immature or in vitro-matured COCs and denuded oocytes were suspended in distilled water and frozenthawed twice to produce cold osmotic shock, centrifuged 
at $10000 \mathrm{~g}$ for $20 \mathrm{~min}$ at $4^{\circ} \mathrm{C}$, and enzyme activities were determined in supernatants. Residual cumulus cells suspended in physiological saline were processed in the same way. Extracts were prepared so that the final amount of each enzyme ensured linear behaviour during activity measurement, thus enabling absorbance per min variation to be calculated.

\section{Determination of alanine and aspartate aminotransferase activities}

Transaminase activities were determined in extracts of immature or in vitro-matured COCs $(n=70)$ and from denuded oocytes $(n=250)$. ALT activity was measured in a spectrophotometer at $340 \mathrm{~nm}$ for $3 \mathrm{~min}$ at $37^{\circ} \mathrm{C}$ in $100 \mathrm{mmol}$ Tris- $\mathrm{HCl}$ buffer $\mathrm{I}^{-1}, \mathrm{pH} 7.3 ; 0.18 \mathrm{mmol}$ $\mathrm{NADH} \mathrm{I} \mathrm{I}^{-1} ; 500 \mathrm{mmol}$ L-alanine $\mathrm{I}^{-1}$; and $15 \mathrm{mmol} \alpha-$ ketoglutarate $\mathrm{I}^{-1}$ in the presence of $(1) \geqslant 1200 \mathrm{U}$ lactate dehydrogenase $\mathrm{I}^{-1}$ (Bergmeyer et al., 1986a). AST activity was measured in a spectrophotometer at $340 \mathrm{~nm}$ for $3 \mathrm{~min}$ at $37^{\circ} \mathrm{C}$ in $80 \mathrm{mmol}$ Tris- $\mathrm{HCl}$ buffer $\mathrm{I}^{-1}$, $\mathrm{pH} 7.8 ; 0.18 \mathrm{mmol} \mathrm{NADH} \mathrm{I}^{-1} ; 240 \mathrm{mmol}$ L-aspartate $\mathrm{I}^{-1}$; and $12 \mathrm{mmol} \alpha$-ketoglutarate $\mathrm{I}^{-1}$ in the presence of $(1) \geqslant 600 \cup$ lactate dehydrogenase $\mathrm{I}^{-1}$ and $(2) \geqslant 420 \mathrm{U}$ malate dehydrogenase $\mathrm{I}^{-1}$ (Bergmeyer et al., 1986b). An enzymatic unit of ALT or AST is defined as the quantity of enzyme that catalyses the oxidation of $1 \mu \mathrm{mol}$ $\mathrm{NADH} \mathrm{min}^{-1}$.

\section{ALT}

Alanine $+\alpha$-Ketoglutarate $\rightarrow$ Pyruvate + Glutamate

(1) Pyruvate $+\mathrm{NADH} \rightarrow$ Lactate $+\mathrm{NAD}$

Aspartate $+\alpha$-Ketoglutarate

AST

$\rightarrow$ Oxaloacetate (Pyruvate $\left.+\mathrm{CO}_{2}\right)+$ Glutamate

(1) Pyruvate $+\mathrm{NADH} \rightarrow$ Lactate $+\mathrm{NAD}$

(2) Oxaloacetate + NADH $\rightarrow$ Malate $+\mathrm{NAD}$

\section{Determination of isocitrate dehydrogenase activity}

$\mathrm{IDH}$ activity was determined in extracts of immature or in vitro-matured COCs $(n=50)$ and from denuded oocytes $(n=100)$. NADP-IDH activity was measured in a spectrophotometer at $340 \mathrm{~nm}$ for $10 \mathrm{~min}$ at $37^{\circ} \mathrm{C}$ in $70 \mathrm{mmol}$ Tris- $\mathrm{HCl}$ buffer I $\mathrm{I}^{-1}, \mathrm{pH} 7.5 ; 1 \mathrm{mmol} \mathrm{MnCl}_{2} \mathrm{I}^{-1}$; $8 \mathrm{mmol} \mathrm{MgCl}_{2} \mathrm{I}^{-1} ; 1.5 \mathrm{mmol}$ isocitrate $\mathrm{I}^{-1} ; 10 \mathrm{mmol}$ citrate $\mathrm{I}^{-1}$; and $0.5 \mathrm{mmol}$ NADP $\mathrm{I}^{-1}$. NAD-IDH activity was measured in the same conditions but NADP was replaced with 2 mmol $\mathrm{NADI}^{-1}, \mathrm{pH} 7.1$, with the addition of $2.0 \mathrm{mmol} \mathrm{ADP} \mathrm{I}^{-1}$ (Alp et al., 1976).

An enzymatic unit of IDH is defined as the quantity of enzyme that catalyses the reduction of $1 \mu \mathrm{mol}$ $\mathrm{NAD}(\mathrm{P}) \mathrm{min}^{-1}$.

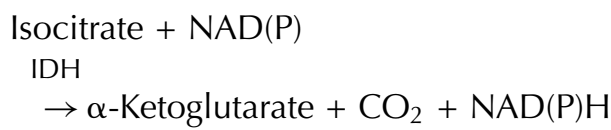

\section{Determination of malate dehydrogenase activity}

$\mathrm{MDH}$ activity was determined in extracts of immature or in vitro-matured COCs $(n=20)$ and from denuded oocytes $(n=50)$. Activity was measured in a spectrophotometer at $340 \mathrm{~nm}$ for $1.5 \mathrm{~min}$ at $30^{\circ} \mathrm{C}$ in $90 \mathrm{mmol}$

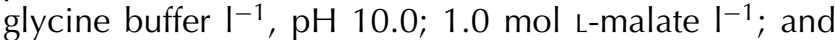
$12.3 \mathrm{mmol}^{\mathrm{N} A D \mathrm{I}^{-1}}$ (Kitto, 1969). An enzymatic unit of $\mathrm{MDH}$ is defined as the quantity of enzyme that catalyses the reduction of $1 \mu \mathrm{mol} N A D \mathrm{~min}^{-1}$.

$$
\begin{gathered}
\mathrm{MDH} \\
\text { Malate }+\mathrm{NAD} \rightarrow \text { Oxaloacetate }+\mathrm{NADH}
\end{gathered}
$$

\section{Determination of total proteins}

Total protein concentrations were determined in enzymatic extract supernatants using the method described by Lowry et al. (1951).

\section{Oxidative substrates and co-enzymes added to the maturation medium}

COCs or denuded oocytes were matured under the described conditions, with addition of oxidative substrates and co-enzymes corresponding to the enzymes under study: (a) $10 \mathrm{mmol}$ L-alanine $\mathrm{I}^{-1}$; (b) $10 \mathrm{mmol}$ L-aspartate $\mathrm{I}^{-1}$; (c) $1.5 \mathrm{mmol}$ isocitrate $\mathrm{I}^{-1}+10 \mathrm{mmol}$ citrate $\mathrm{I}^{-1}$; (d) $1.5 \mathrm{mmol}$ isocitrate $\mathrm{I}^{-1}+10 \mathrm{mmol}$ citrate $\mathrm{I}^{-1}+12.5 \mathrm{mmol} \mathrm{NAD} \mathrm{I}^{-1}$; (e) $1.5 \mathrm{mmol}$ isocitrate $\mathrm{I}^{-1}+10 \mathrm{mmol}$ citrate $\mathrm{I}^{-1}+12.5 \mathrm{mmol}$ NADP $\mathrm{I}^{-1}$; (f) $1 \mathrm{mmol}$ oxaloacetate $\mathrm{I}^{-1}$; (g) $1 \mathrm{mmol}$ malate $\mathrm{I}^{-1}$; (h) $1 \mathrm{mmol}$ malate $\mathrm{I}^{-1}+12.5 \mathrm{mmol} \mathrm{NAD} \mathrm{I}^{-1}$; (i) $12.5 \mathrm{mmol}$ $\mathrm{NAD} \mathrm{I}^{-1}$; and (j) $12.5 \mathrm{mmol} \mathrm{NADP} \mathrm{I}^{-1}$.

The percentage of meiotic maturation was evaluated in each case.

\section{Experimental design and statistical analysis}

Enzymatic activity was expressed as enzymatic units and specific activity. Enzymatic units were expressed in units per COC, denuded oocyte or cumulus. Determination of total proteins in enzymatic extracts enabled the comparison of enzymatic activity between denuded oocytes and cumulus cells expressed in units per $\mu g$ protein (specific activity). Data were expressed as means \pm SEM. Intra-assay and interassay variability were estimated according to Rodbard (1974) and expressed as co-efficient of variation.

The enzymatic activity of each enzyme in COCs matured in vitro was determined by comparing immature and matured COCs using Student's $t$ test. Activities in denuded oocytes and cumulus cells arising from 
Table 1. Alanine aminotransferase (ALT), aspartate aminotransferase (AST), NADP-dependent isocitrate dehydrogenase (NADP-IDH) and malate dehydrogenase $(\mathrm{MDH})$ activities in immature and in vitro-matured cumulus-oocyte complexes (COCs)

COCs

\begin{tabular}{|c|c|c|c|c|}
\hline \multirow[b]{2}{*}{ Enzyme } & \multicolumn{2}{|c|}{ Units per COC } & \multicolumn{2}{|c|}{ Units $\mu g^{-1}$ protein } \\
\hline & Immature & Matured & Immature & Matured \\
\hline ALT & $(1.22 \pm 0.13) 10^{-4, \mathrm{a}}$ & $(1.02 \pm 0.08) 10^{-4, a}$ & $(1.47 \pm 0.14) 10^{-4, b}$ & $(0.38 \pm 0.02) 10^{-4, \mathrm{c}}$ \\
\hline AST & $(1.21 \pm 0.13) 10^{-4, a}$ & $(1.17 \pm 0.10) 10^{-4, a}$ & $(1.46 \pm 0.14) 10^{-4, b}$ & $(0.43 \pm 0.03) 10^{-4, \mathrm{c}}$ \\
\hline NADP-IDH & $(8.21 \pm 0.48) 10^{-5, a}$ & $(8.69 \pm 0.52) 10^{-5, a}$ & $(9.65 \pm 0.56) 10^{-5, b}$ & $(3.48 \pm 0.21) 10^{-5, \mathrm{c}}$ \\
\hline $\mathrm{MDH}$ & $(2.03 \pm 0.19) 10^{-4, a}$ & $(2.08 \pm 0.13) 10^{-4, a}$ & $(2.54 \pm 0.23) 10^{-4, b}$ & $(0.83 \pm 0.05) 10^{-4, \mathrm{c}}$ \\
\hline
\end{tabular}

Activities are measured in units per COC as specific activity (units $\mu \mathrm{g}^{-1}$ protein). Values are means \pm SEM of 11-13 replicates.

${ }^{a}$ Values with the same superscript are not significantly different.

${ }^{b c}$ Values with different superscripts are significantly different $(P<0.05)$.

immature and matured COCs were compared in a factorial design to evaluate the enzymatic activity contribution by either type of COC cell.

Statistical analyses of meiotic maturation rates were made by chi-squared analysis.

A $P$ value $<0.05$ was considered significant.

\section{Results}

In $10 \%$ of samples used to evaluate meiotic maturation of COCs, the percentage of IVM ranged from $79.0 \%$ to $84.4 \%$. Activities expressed in enzymatic units remained constant during COC IVM in all enzymes studied, in contrast to the decrease observed in specific activity $(P<0.05$; Table 1$)$.

ALT and AST units remained constant in the oocyte and cumulus cells during IVM; the cumulus cells reached on average 36-fold and ninefold greater ALT and AST units than the oocyte, respectively $(P<0.05)$. AST activity in the oocyte was approximately 4.4 times greater than that recorded for ALT $(P<0.05)$, unlike in cumulus cells, in which similar activity was maintained for both enzymes (Fig. 1). Specific activities of both transaminases increased in the oocyte and diminished in cumulus cells during IVM $(P<0.05)$; however, ALT activity was invariably higher in cumulus cells and AST activity was higher in the matured oocyte compared with matured cumulus cells ( $P<0.05$; Fig. 1$)$.

On adding substrates corresponding to ALT or AST to the maturation medium, the percentage of COCs reaching meiotic maturation in the presence of alanine or aspartate did not differ from that of controls, but increased with both substrates for the denuded oocytes $(P<0.05$; Fig. 2).

No NAD-IDH activity was recorded in immature and in vitro-matured COCs under the assay conditions used. NADP-IDH units remained constant in the oocyte and cumulus cells during IVM; the cumulus cells reached on average 14-fold more enzymatic units than the oocyte $(P<0.05)$. Specific activity increased in the oocyte $(P<0.05)$ and diminished in cumulus cells during IVM $(P<0.05)$, reaching similar activities in the matured stage (Fig. 3).

On adding substrates, co-enzymes or both corresponding to NADP-IDH and NAD-IDH to the maturation medium, the percentage of COCs reaching meiotic maturation was not different for the different treatments. However, the percentage of denuded oocytes reaching meiotic maturation increased versus the control in the presence of isocitrate + citrate + NADP $(P<0.05)$, but remained unchanged when isocitrate + citrate, isocitrate + citrate + NAD, NAD or NADP was added (Fig. 4).

$\mathrm{MDH}$ units remained constant in the oocyte and in cumulus cells during IVM; the cumulus cells reached on average 22-fold more enzymatic units than the oocyte $(P<0.05)$. Specific activity increased in the oocyte and diminished in cumulus cells during in vitro maturation $(P<0.05)$, reaching the same activities in the matured stage (Fig. 5).

On adding substrates, co-enzymes or both corresponding to enzyme MDH to the maturation medium, the percentage of COCs reaching meiotic maturation was not different for the different treatments. However, the percentage of denuded oocytes reaching meiotic maturation increased with regard to the control in the presence of oxaloacetate or malate + NAD $(P<0.05)$, but remained unchanged in the presence of malate or NAD (Fig. 6).

Repeatability of data for enzymatic units and specific activity were similar in COCs, denuded oocytes and cumulus cells for each enzyme. For ALT, intra-assay co-efficient of variation $=20-41 \%$ and interassay coefficient of variation $=0-20 \%$; for AST, intra-assay co-efficient of variation $=15-40 \%$ and interassay coefficient of variation $=0-22 \%$; for NADP-IDH, intraassay co-efficient of variation $=13-26 \%$ and interassay co-efficient of variation $=0-19 \%$; and for $\mathrm{MDH}$, intraassay co-efficient of variation $=11-42 \%$ and interassay co-efficient of variation $=0-19 \%$. 
(a)

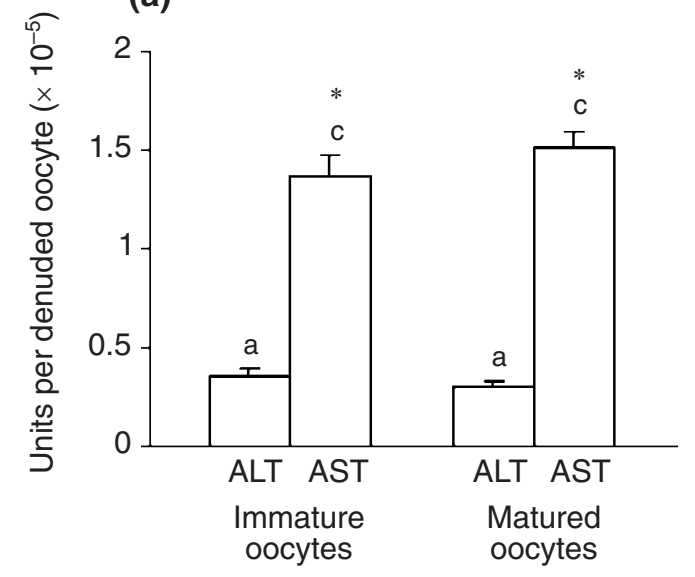

(c)

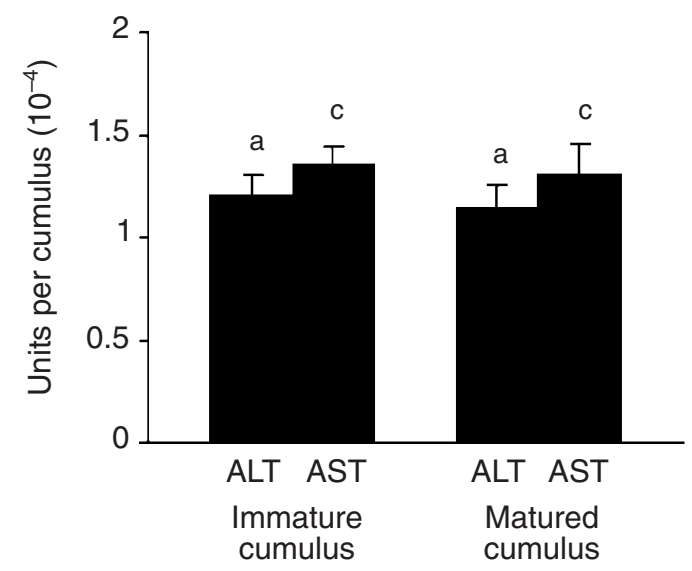

(b)

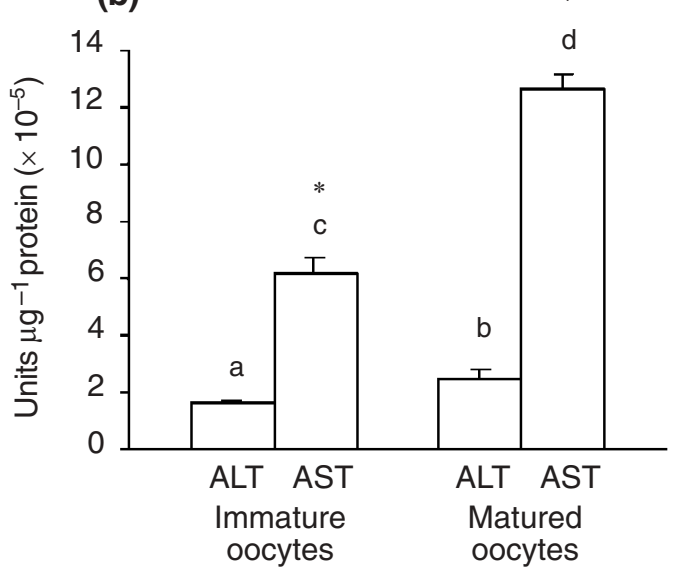

(d)

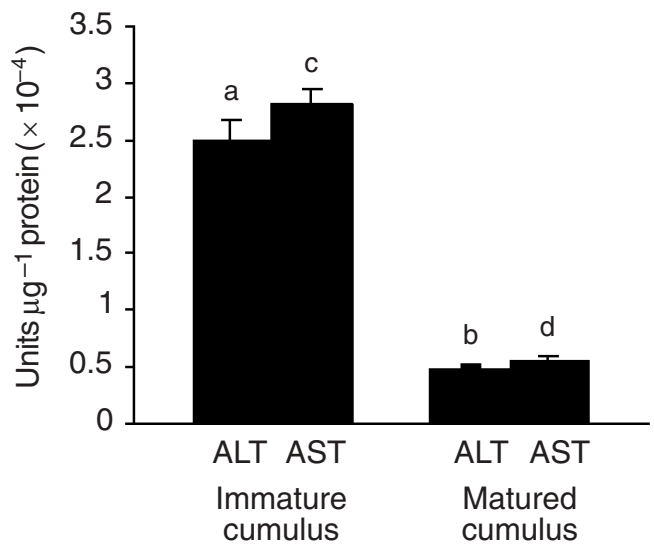

Fig. 1. Alanine aminotransferase (ALT) and aspartate aminotransferase (AST) activities in denuded oocytes ( $\square$ ) and cumulus cells $(\mathbf{\square})$ from immature and in vitro-matured cumulus-oocyte complexes. Activities are measured $(\mathrm{a}, \mathrm{C})$ in units per denuded oocyte or cumulus and $(b, d)$ as specific activity (units $\mu g^{-1}$ protein). Values are means \pm SEM of 10-12 replicates. ${ }^{\text {a-d }}$ Bars with different superscripts are significantly different $(P<0.05)$; ${ }^{*}$ significantly different from corresponding ALT activity $(P<0.05)$. There are significant differences between denuded oocytes and corresponding cumulus cells for both enzymes $(P<0.05)$.

\section{Discussion}

It is well documented that cumulus cells supply oxidative substrates to the oocyte during maturation (Buccione et al., 1990; Brackett and Zuelke, 1993; Cetica et al., 1999b). The present study determined the activity of ALT, AST, IDH and MDH in extracts from oocytes and cumulus cells. The specific oxidative substrate was added for each studied enzyme, replacing the function of cumulus cells during denuded oocyte maturation, to confirm that the enzyme is participating in the maturation process.

ALT, AST, NADP-IDH and MDH activities expressed as units per $\mathrm{COC}$ remained unchanged during maturation because both denuded oocyte and cumulus units did not vary during this process. It has been reported that the amount of protein present in bovine cumulus cells increases gradually during the $24 \mathrm{~h}$ of IVM, in part due to the increase in the number of cumulus cells $(\mathrm{Wu}$ et al., 1996; Cetica et al., 2001). However, a slight but significant decrease in total protein concentration in bovine denuded oocyte extracts was recorded (Cetica et al., 2001), as well as in protein synthesis rate (Wu et al., 1996; Gandolfi et al., 1998). These findings explain the decrease in cumulus cells and the increase in denuded oocyte specific activity recorded for the studied enzymes in the course of maturation. It may therefore be inferred that the enzymatic activity of cumulus cells would be gradually lost when cumulus expansion occurs during maturation. The studied enzymes would not be involved in the detected loss of oocyte proteins, indicating that the gamete maintains its enzymatic machinery even when dissociated from cumulus cells during maturation, as previously observed for other enzymes (Cetica et al. 2001, 2002).

Glycolysis is considered to be the predominant metabolic pathway for glucose utilization in cumulus 


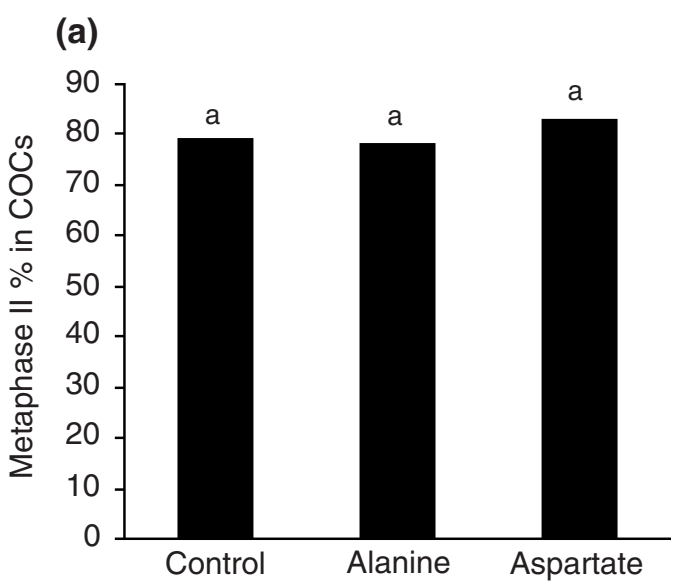

(b)

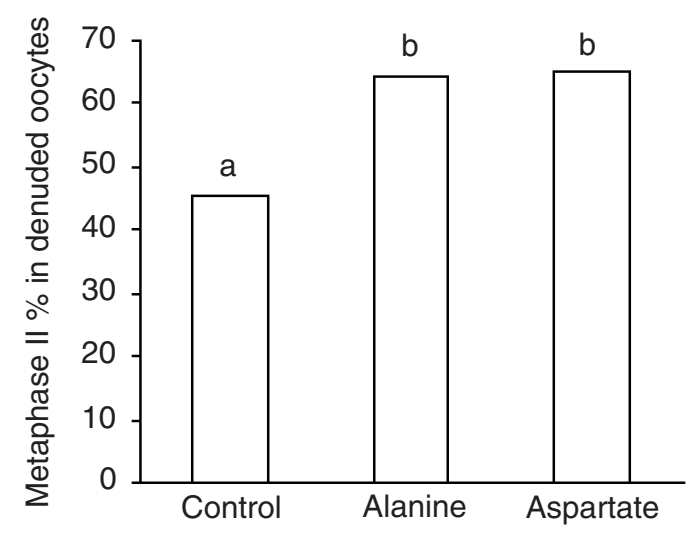

Fig. 2. Meiotic maturation rate in (a) cumulus-oocyte complexes (COCs; $\mathbf{\square}$ ) and (b) denuded oocytes $(\square)$ cultured with different supplements; $n=167-186$ for each treatment. ${ }^{\text {ab }}$ Bars with different superscripts are significantly different $(P<0.05)$.

cells (Zuelke and Brackett, 1992; Cetica et al., 1999b, 2002; Sutton et al., 2003a), with raised activity of phosphofructokinase, the main enzyme regulating the rate of the pathway (Cetica et al., 2002). In contrast, denuded oocytes display very low levels of glucose uptake, glycolytic activity, glucose oxidation (Zuelke and Brackett, 1992; Rieger and Loskutoff, 1994; Saito et al., 1994) and low phosphofructokinase activity (Cetica et al., 2002). Hence, it was suggested that the fate of glucose within cumulus cells is mainly the production of pyruvate or lactate, both preferential oocyte substrates oxidized in the TCA cycle (Cetica et al., 1999b; Eppig et al., 2000; Khurana and Niemann, 2000).

Similarly high ALT and AST activities were recorded in cumulus cells, comparable to that reported for phosphofructokinase. Such raised transaminase activity could be linked to the synthesis of amino acids in these cells with a high rate of protein synthesis or oxidative substrate production to be supplied to the oocyte. It has been suggested that in rodents, amino acids may be utilized by oocytes as an energy source with cumulus cells, and play a major role in amino acid flux into the oocyte (Colonna and Mangia, 1983). Transaminase activity in the oocyte was increased with regard to phosphofructokinase, and was on average 2.8 and 12.4 times greater for ALT and AST, respectively. In turn, AST activity in the oocyte was significantly greater than that of ALT, reaching on average 4.4-fold greater activity. These results may indicate a leading function of aspartate in oocyte energy metabolism due to the conversion to oxaloacetate to be used in the TCA cycle or for participation in the malate-aspartate shuttle system in the oxidation of reduction equivalents (Fig. 7), for example those generated partly by lactate dehydrogenase-1 isoenzyme in lactate oxidation (Cetica et al., 1999b).

An increased percentage of meiotic maturation of oocytes denuded in the presence of alanine or aspartate in the maturation medium confirms their use as oxidative substrates for the oocytes or the participation of these compounds in the synthesis of protein factors involved in the control of maturation. Alanine and aspartate are among the amino acids classified as non-essential by Eagle (1959). In fact, non-essential amino acids should be components of bovine maturation and embryo culture media in order to achieve a high percentage of successful IVF cycles and embryos reaching the blastocyst stage (Gardner, 1998; Rose-Hellekant et al., 1998; Lim et al., 1999).

When IDH activity was studied in bovine COCs, NADP-dependent isoenzyme activity was observed, but not activity of the NAD-dependent isoform. This finding need not rule out NAD-IDH activity, but rather implies that due to its scarce quantity it proves undetectable under assay conditions, in which sample concentration is a limiting factor. However, meiotic maturation data from denuded oocytes appear to confirm these results, because an increase was observed only in maturation percentage in the presence of isocitrate + citrate + NADP; when isocitrate + citrate + NAD was added there was no change. In the absence of NADP, isocitrate + citrate failed to increase the maturation percentage, demonstrating that the co-enzyme must be present so that substrates can be used by the oocyte.

It should be highlighted that in both IDH enzymatic activity determination and IVM assays, high citrate concentrations were added because it acts as an enzyme activator or it displaces the reversible reaction of the (1) aconitase toward isocitrate formation to ensure its uptake by (2) IDH, rather than due to the presence of aconitase.

(1) (2)

$$
\text { Citrate } \rightarrow \text { Isocitrate } \rightarrow \alpha \text {-Ketoglutarate }
$$

NADP-IDH units in cumulus cells are 1.5-fold lower than those reported for phosphofructokinase (Cetica et al., 2002), in agreement with the observation that glycolysis is the main pathway for glucose utilization in cumulus cells, the level of oxygen uptake proving 
(a)

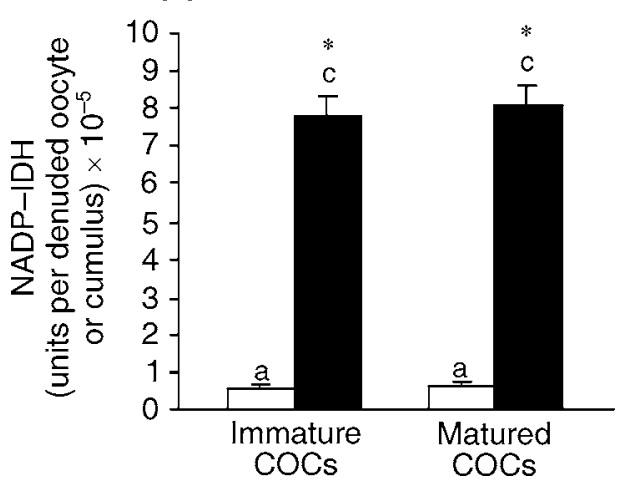

(b)

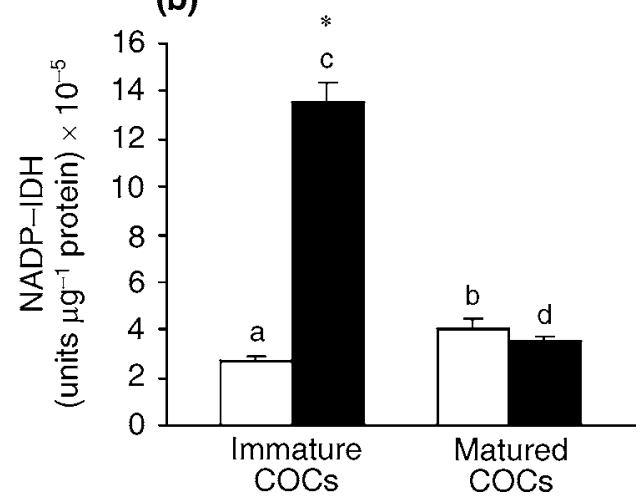

Fig. 3. NADP-dependent isocitrate dehydrogenase (NADP-IDH) activity in denuded oocytes ( $\square$ ) and cumulus cells ( $\mathbf{\square})$ from immature and in vitro-matured cumulus-oocyte complexes (COCs). Activity is

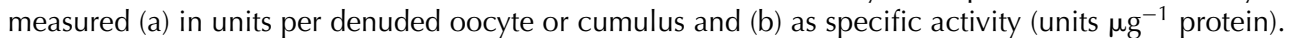
Values are means \pm SEM of $10-13$ replicates. ${ }^{a-d}$ Bars with different superscripts are significantly different $(P<0.05)$; ${ }^{*}$ significantly different from NADP-IDH activity of corresponding denuded oocyte $(P<0.05)$.

(a)

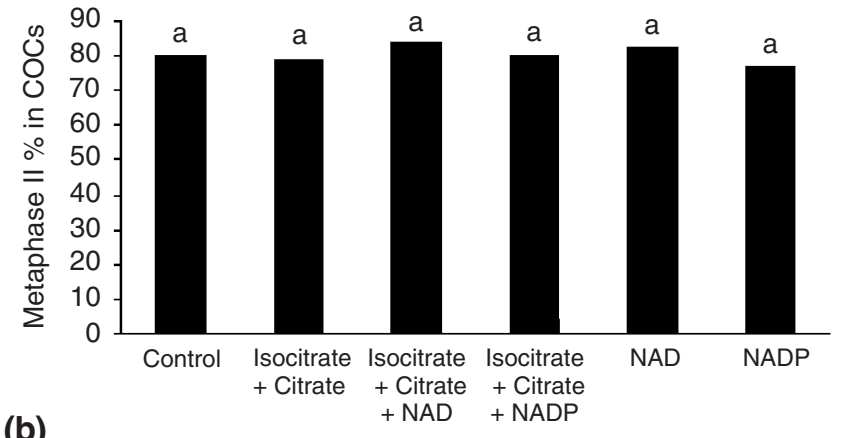

(b)

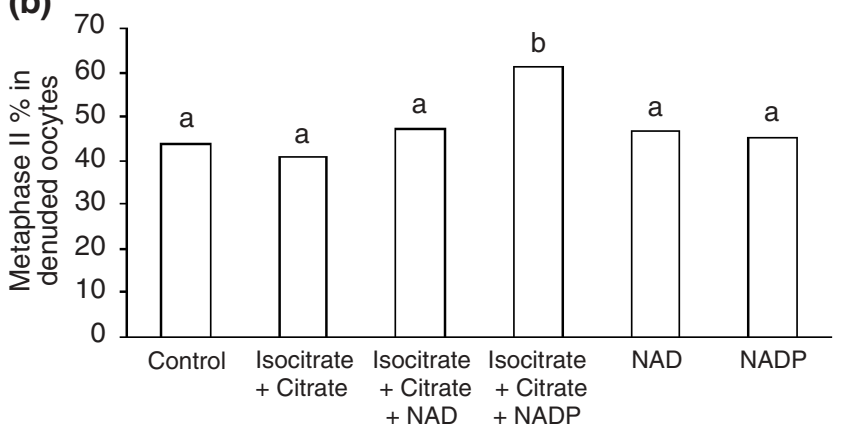

Fig. 4. Meiotic maturation rate in (a) cumulus-oocyte complexes (COCs; $\mathbf{\square})$ and (b) denuded oocytes $(\square)$ cultured with different supplements; $n=168-202$ for each treatment. ${ }^{\text {ab }}$ Bars with different superscripts are significantly different $(P<0.05)$.

very low (Sutton et al., 2003b). In contrast, enzyme activity in the oocyte is on average 4.8 times higher than in phosphofructokinase, denoting a greater relative importance of the TCA cycle with regard to glycolysis in the female gamete (Fig. 7).

In several mammalian tissues and cells, considerably greater activity of NADP-IDH with regard to NADIDH (ranging from ten- to 400 -fold) has been reported, indicating that both enzymes are particularly involved in isocitrate dehydrogenation for energy production when the TCA cycle flow approaches peak value. These tissues and cells are characterized by possessing high activity of the catabolically oriented cycle in order to sustain a constant energy supply, as heart, red skeletal muscle (Alp et al., 1976) and spermatozoa (Brooks, 1978). The oocyte during maturation and the embryo during development may also respond to these metabolic features. In addition to its role in cumulus cells and oocytes, NADP-IDH could participate in the generation of NADPH for reductive synthesis, supplementing that produced by glucose-6-phosphate dehydrogenase, the key enzyme in the control of the pentose pathway (Cetica et al., 2002).

Although $\mathrm{MDH}$ is not considered an enzyme that controls the flow of the TCA cycle, it nonetheless plays a key role in the operation of the TCA cycle because it catalyses a reaction distant from the equilibrium that regenerates oxaloacetate to initiate the cycle (Clarenburg, 1992). Enzyme activity in the oocyte was high and could be linked not only with the cycle for oxidative energy supply but also with the malateaspartate shuttle system for transport of reduction equivalents through the internal mitochondrial membrane. Combined MDH and AST activities, the levels of which are markedly similar, support the above proposal of the presence of this shuttle system in the bovine oocyte (Fig. 7). In tissues such as heart, liver and kidney, with a high capacity to metabolize lactate, the shuttle system described is that of malate-aspartate (Dawson, 1979; Lehninger et al., 1997). Co-enzyme NADH, produced when lactate is oxidized to pyruvate by the action of lactate dehydrogenase, is re-oxidized by the participation of enzymes $\mathrm{MDH}$ and AST. The oocyte would also respond to these features with raised activity of lactate dehydrogenase- 1 isoenzyme, $\mathrm{MDH}$ and AST. 
(a)

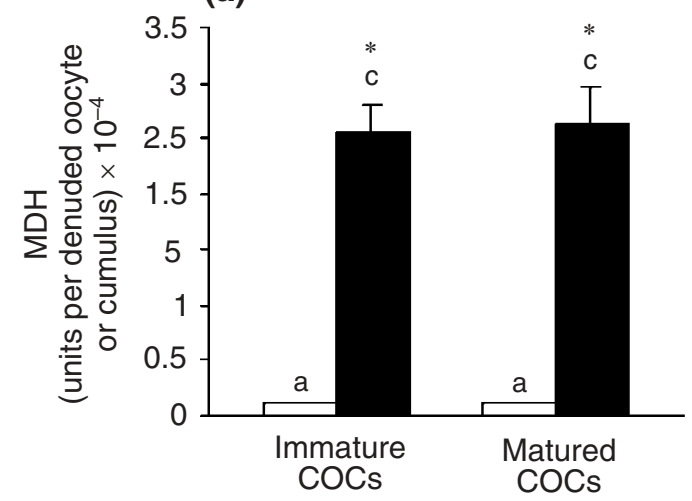

(b)

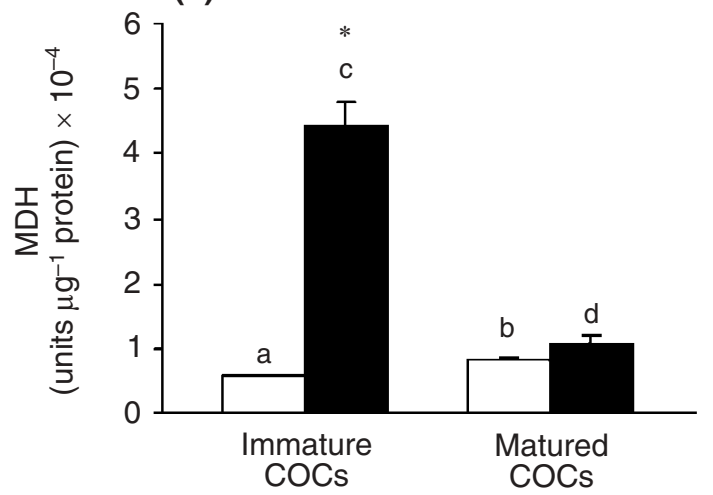

Fig. 5. Malate dehydrogenase (MDH) activity in denuded oocytes $(\square)$ and cumulus cells ( $\square$ ) from immature and in vitro-matured cumulus-oocyte complexes (COCs). Activity is measured (a) in units per denuded oocyte or cumulus and (b) as specific activity (units $\mu \mathrm{g}^{-1}$ protein). Values are means \pm SEM of 10-11 replicates. ${ }^{\mathrm{a}-\mathrm{d} B a r s}$ with different superscripts are significantly different $(P<0.05)$; ${ }^{*}$ significantly different from $\mathrm{MDH}$ activity of corresponding denuded oocyte $(P<0.05)$.

(a)

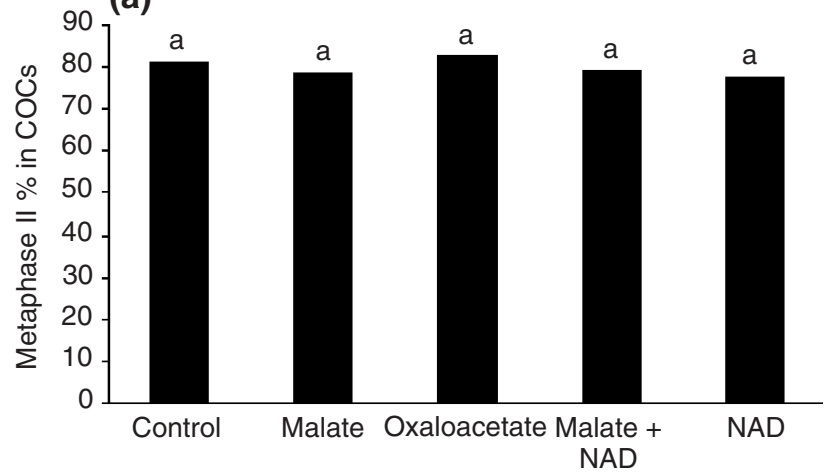

(b)

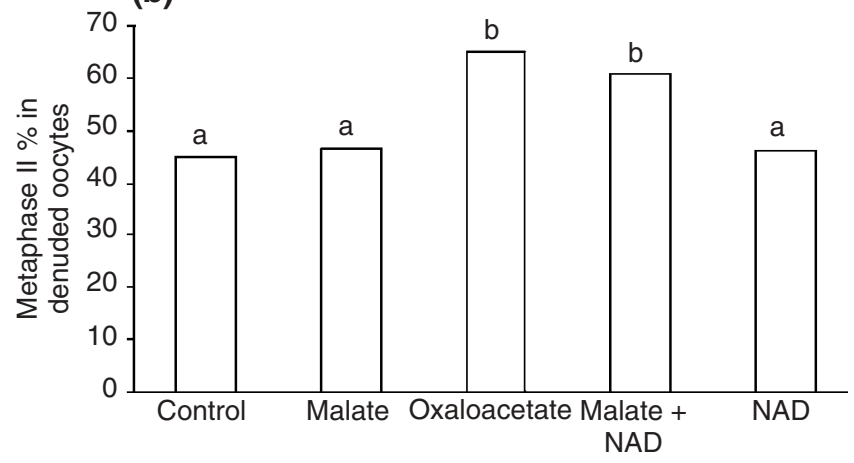

Fig. 6. Meiotic maturation rate in (a) cumulus-oocyte complexes (COCs; $\mathbf{\square}$ ) and (b) denuded oocytes $(\square)$ cultured with different supplements; $n=160-191$ for each treatment. ${ }^{a b}$ Bars with different superscripts are significantly different $(P<0.05)$.

However, MDH activity recorded in cumulus cells could participate in malate supply to the oocyte as an oxidative substrate starting from products derived from glucose oxidation by the glucolytic pathway and also re-oxidize co-enzyme NAD to ensure the continuity of glucolytic flow (Fig. 7), probably supplementing lactate dehydrogenase activity previously recorded in bovine cumulus cells (Cetica et al., 1999b).

The percentage of denuded oocytes reaching meiotic maturation increased in the presence of oxaloacetate, as also observed in mice (Biggers et al., 1967), indicating that this compound can be used by the oocyte as an oxidative substrate. The presence of malate in the maturation medium failed to increase the number of mature oocytes, requiring addition of NAD to improve the percentage of oocytes reaching maturation. In all likelihood, this takes place due to oxaloacetate formation starting from malate when the supply of NAD is sufficient.

Increased percentage of denuded bovine oocytes reaching meiotic maturation in media supplemented with citrate + isocitrate and with malate by addition of oxidized co-enzymes NADP and NAD, respectively, was also previously observed for lactate with the addition of NAD (Cetica et al., 1999b). This beneficial effect was not recorded in the meiotic maturation of COCs, indicating that cumulus cells play a key regulatory role in the redox state of the oocyte. These cells could supply the oocyte with co-enzymes or their precursors or contribute to maintain redox equilibrium for normal gamete function. In rodents, it has been found that coenzyme concentrations present in the oocyte are low (Wales, 1975) and there is ribonucleoside uptake by the oocyte mediated by cumulus and granulosa cells (Heller and Schultz, 1980; Heller et al., 1981; Brower and Schultz, 1982). In ovine embryos, NAD:NADH and pyruvate:lactate ratios may determine the cytosol redox state, thus altering the mitochondrial redox state and the normal operation of the TCA cycle (Lieber, 1991; Thompson et al., 1993).

To date, there is minimal information regarding the metabolic profile of COCs during maturation. The present data extend knowledge of the utilization of amino 


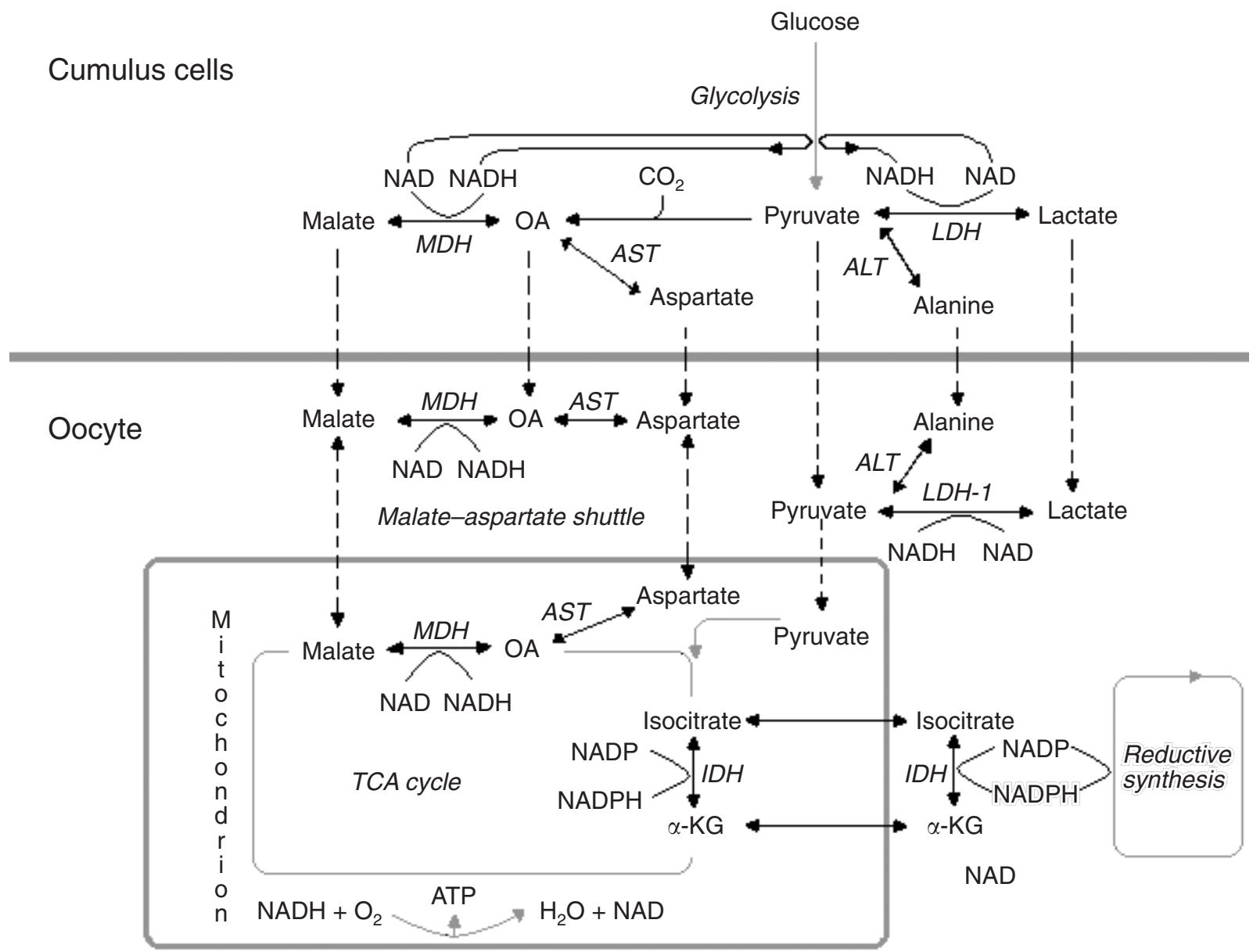

Respiratory chain

Fig. 7. Proposed model of the main pathways for amino acid and carboxylic acid oxidation in cumulus-oocyte complexes. PFK: phosphofructokinase; LDH: lactate dehydrogenase; ALT: alanine aminotransferase; AST: aspartate aminotransferase; $\mathrm{IDH}$ : isocitrate dehydrogenase; $\mathrm{MDH}$ : malate dehydrogenase; OA: oxaloacetate; $\alpha$-KG: $\alpha$-ketoglutarate; TCA: tricarboxylic acid.

acids and carboxylic acids within the whole complex. It is possible that further investigations in the control of the enzymatic activity related to COC metabolism may aid in the optimization of the culture conditions during IVM and the subsequent in vitro culture.

In summary, raised transaminase activities detected in cumulus cells indicate an important dynamism in the metabolism of amino acids. Alanine and aspartate are involved in bovine oocyte IVM. The participation of NADP-IDH and MDH and the use of TCA cycle intermediaries (oxaloacetate, isocitrate, malate) would confirm the aerobic activity of the oocyte. High $\mathrm{MDH}$ and AST activities support the proposal of the presence of the malate-aspartate shuttle system in the bovine oocyte. To date, the oocyte is believed to rely on cumulus cells to metabolize initially glucose to pyruvate as the preferred oxidative substrate of the oocyte. However, the present data indicate that the oocyte proves more versatile in the use of diverse oxidative substrates depending on its redox state. The appropriate balance among lactate, pyruvate or alanine; malate, oxaloacetate or aspartate and $\mathrm{NAD}(\mathrm{P})$ or $\mathrm{NAD}(\mathrm{P}) \mathrm{H}$ would therefore be decisive conditions for the use of these oxidative substrates by the oocyte during IVM.

This work was supported by a grant from the University of Buenos Aires. The authors thank JICA (Japanese International Cooperation Agency) for technology transfer and equipment, Deltacar and El 40 abattoirs for ovaries, Astra Laboratories for ultra-pure water, C. Gutnisky for her technical assistance and L. Marangunich for her statistical suggestions.

\section{References}

Alp P, Newsholme E and Zammit V (1976) Activities of citrate synthase and $\mathrm{NAD}^{+}$-linked and $\mathrm{NADP}^{+}$-linked isocitrate dehydrogenase in muscle from vertebrates and invertebrates The Biochemical Journal 154689 700 
Bavister B, Rose-Hellekant T and Pinyopummintr T (1992) Development of in vitro matured-in vitro fertilized bovine embryos into morulae and blastocysts in defined culture media Theriogenology 37127 145

Bergmeyer H, Horder $\mathbf{M}$ and Rej J (1986a) International Federation of Clinical Chemistry (IFCC) scientific committee, analytical section: approved recommendation (1985) on IFCC methods for the measurement of catalytic concentration of enzymes. Part 3. IFCC method for alanine aminotransferase (L-alanine: 2-oxoglutarate aminotransferase, EC 2.6.1.2) Journal of Clinical Chemistry and Clinical Biochemistry 24 481-495

Bergmeyer H, Horder M and Rej J (1986b) International Federation of Clinical Chemistry (IFCC) scientific committee, analytical section: approved recommendation (1985) on IFCC methods for the measurement of catalytic concentration of enzymes. Part 2. IFCC method for aspartate aminotransferase (I-aspartate: 2-oxoglutarate aminotransferase, EC 2.6.1.1) Journal of Clinical Chemistry and Clinical Biochemistry 24 497-510

Biggers J, Whittingham D and Donahue R (1967) The pattern of energy metabolism in the mouse oocyte and zygote Proceedings National Academy of Sciences USA 58 560-567

Brackett B and Zuelke K (1993) Analysis of factors involved in the in vitro production of bovine embryos Theriogenology 39 43-64

Brooks D (1978) Activity and androgenic control of enzymes associated with the tricarboxylic acid cycle, lipid oxidation and mitochondrial shuttles in the epididymis and epididymal spermatozoa The Biochemical Journal $174741-752$

Brower P and Schultz R (1982) Intercellular communication between granulosa cells and mouse oocytes: existence and possible nutritional role during oocyte growth Developmental Biology 90144 153

Buccione R, Schoeder A and Eppig J (1990) Interactions between somatic cells and germ cells throughout mammalian oogenesis Biology of Reproduction 43 543-547

Cetica P, Dalvit G and Beconi M (1999a) Study of evaluation criteria used for in vitro bovine oocyte selection and maturation Biocell 23 125-133

Cetica P, Pintos L, Dalvit G and Beconi M (1999b) Effect of lactate dehydrogenase activity and isoenzyme localization in bovine oocytes and utilization of oxidative substrates on in vitro maturation Theriogenology $51541-550$

Cetica P, Pintos L, Dalvit G and Beconi M (2001) Antioxidant enzyme activity and oxidative stress in bovine oocyte in vitro maturation IUBMB Life 51 57-64

Cetica P, Pintos L, Dalvit G and Beconi M (2002) Activity of key enzymes involved in glucose and triglyceride catabolism during bovine oocyte maturation in vitro. Reproduction 124 675-681

Clarenburg R (1992) Carbohydrate metabolism. In Physiological Chemistry of Domestic Animals pp 239-291 Ed. R Reinhardt. Mosby Year Book Inc., St Louis

Colonna R and Mangia F (1983) Mechanisms of amino acids uptake in cumulus-enclosed mouse oocytes Biology of Reproduction $\mathbf{2 8}$ 797-803

Dawson A (1979) Oxidation of cytosolic NADH during aerobic metabolism in mammalian cells Trends in Biochemical Sciences 4171 179

Eagle H (1959) Amino acids metabolism in mammalian cell cultures Science $130423-437$

Eppig J, Hosoe M, O'Brien M, Pendola F, Requena A and Watanabe S (2000) Conditions that affect acquisition of developmental competence by mouse oocytes in vitro: FSH, insulin, glucose and ascorbic acid Molecular and Cellular Endocrinology 163 109-116

Fatehi A, Zeinstra E, Kooij R, Colenbrander B and Bevers M (2002) Effect of cumulus cell removal of in vitro matured bovine oocytes prior to in vitro fertilization on subsequent cleavage rate Theriogenology 57 13471355

Gandolfi F (1998) Embryo development as a function of oocyte competence. In Gametes: development and function pp 337-353 Eds A Lauria, F Gandolfi, G Enne and L Gianaroli. Tabloid SRL, Rome
Gardner D (1998) Changes in requirements and utilization of nutrients during mammalian preimplantation embryo development and their significance in embryo culture Theriogenology 49 83-102

Hansford R (1980) Control of mitochondrial substrate oxidation Curren Topics in Bioenergetics 10 217-278

Heller D and Schultz R (1980) Ribonucleoside metabolism by mouse oocytes: metabolic cooperativity between the fully grown oocyte and cumulus cells The Journal of Experimental Zoology 214355 364

Heller D, Cahill D and Schultz R (1981) Biochemical studies of mammalian oogenesis: metabolic cooperativity between granulosa cells and growing mouse oocytes Developmental Biology 84 455-464

Khurana $\mathbf{N}$ and Niemann $\mathbf{H}$ (2000) Effects of oocyte quality, oxygen tension, embryo density, cumulus cells and energy substrates on cleavage and morula/blastocyst formation of bovine embryos Theriogenology 54741 756

Kitto G (1969) Intra- and extramitochondrial malate dehydrogenase from chicken and tuna heart Methods in Enzymology 13 107-116

Krisher R and Bavister B (1998) Responses of oocytes and embryos to the culture environment Theriogenology 49 103-114

Lehninger A, Nelson D and Cox M (1997) Oxidative phosphorylation and photophosphorylation. In Principles of Biochemistry pp 543-597 Ed. V Neal. Worth Publishers, New York

Lieber C (1991) Alcohol, liver, and nutrition Journal of the American College of Nutrition 10 602-632

Lim J, Lee B, Lee E, Chung H, Ko J, Park S, Cha K and Hwang W (1999) In vitro maturation and in vitro fertilization of bovine oocytes cultured in a chemically defined, protein-free medium: effects of carbohydrates and amino acids Reproduction, Fertility and Development 11 127-132

Lowry O, Rosebrough N, Farr A and Randall R (1951) Protein measurement with the Folin phenol reagent The Journal of Biological Chemistry 193 265-275

Rieger D and Loskutoff N (1994) Changes in the metabolism of glucose, pyruvate, glutamine and glycine during maturation of cattle oocytes Journal of Reproduction and Fertility 100 257-262

Rodbard D (1974) Statistical quality control and routine data processing for radioimmunoassays and immunoradiometric assays Clinical Chemistry 20 1255-1270

Rose-Hellekant T, Libersky-Williamson E and Bavister B (1998) Energy substrates and amino acids provided during in vitro maturation of bovine oocytes alter acquisition of developmental competence Zygote 6 285294

Saito T, Hiroi M and Kato T (1994) Development of glucose utilization studied in single oocytes and preimplantation embryos from mice Biology of Reproduction 50 266-270

Schwartz M (1971) Clinical aspects of aspartate and alanine aminotransferases Methods in Enzymology 17B 866-875

Sutton M, Cetica P, Beconi M, Kind K, Gilchrist R and Thompson J (2003a) Influence of oocyte-secreted factors and culture duration on the metabolic activity of bovine cumulus cell complexes Reproduction 126 27-34

Sutton M, Cetica P, Gilchrist R and Thompson J (2003b) The metabolic profiles of bovine cumulus-ocyte complexes: effects of oocyte-secreted factors and stimulation of cumulus expansion Theriogenology $\mathbf{5 9} 500$

Sutton M, Gilchrist R and Thompson J (2003c) Effects of in vitro environments on the metabolism of the cumulus-oocyte complex and its influence on oocyte developmental capacity Human Reproduction Update 9 35-48

Tarkowski A (1966) An air-drying method for chromosome preparations from mouse eggs Cytogenetics 5 394-400

Thompson J, Bell A, Pugh P and Tervit H (1993) Metabolism of pyruvate by pre-elongation sheep embryos and effect of pyruvate and lactate concentrations during culture in vitro. Reproduction, Fertility and Development 5 417-423

Torchinsky Y (1987) Transamination: its discovery, biological and clinical aspects (1937-1987) Trends in Biochemical Sciences 12 115-117

Wales R (1975) Maturation of the mammalian embryo: biochemical aspects Biology of Reproduction 12 66-81 
Wu B, Ignotz G, Currie W and Yang X (1996) Temporal distinctions in the synthesis and accumulation of proteins by oocytes and cumulus cells during maturation in vitro of bovine oocytes Molecular Reproduction and Development 45 560-565

Zhang L, Jiang J, Wozniak P, Yang X and Godke R (1995) Cumulus cell function during bovine oocyte maturation, fertilization, and embryo development in vitro. Molecular Reproduction and Development 40 338-344

Zuelke K and Brackett B (1992) Effects of luteinizing hormone on glucose metabolism in cumulus enclosed bovine oocytes matured in vitro. Endocrinology 131 2690-2696
Zuelke K and Brackett B (1993) Increased glutamine metabolism in bovine cumulus cell-enclosed and denuded oocytes after in vitro maturation with luteinizing hormone Biology of Reproduction 48815 820

Received 3 June 2003.

First decision 28 July 2003.

Revised manuscript received 11 August 2003.

Accepted 3 September 2003. 